\title{
Adverse Prognostic Factors of Advanced Esophageal Cancer in Patients Undergoing Induction Therapy with Docetaxel, Cisplatin and 5-Fluorouracil
}

\author{
MASANOBU NAKAJIMA ${ }^{1}$, HIROTO MUROI ${ }^{1}$, MAIKO KIKUCHI ${ }^{1}$, \\ MASAKAZU TAKAHASHI ${ }^{1}$, KEISUKE IHARA ${ }^{1}$, YOSUKE SHIDA ${ }^{1}$, EIGO KURAYAMA ${ }^{1}$, \\ HIDEO OGATA ${ }^{1}$, SATORU YAMAGUCHI ${ }^{1}$, KINRO SASAKI $^{1}$, MAKOTO SAKAI ${ }^{2}$, \\ MAKOTO SOHDA $^{2}$, TATSUYA MIYAZAKI ${ }^{2}$, HIROYUKI KUWANO ${ }^{2}$ and HIROYUKI KATO ${ }^{1}$ \\ ${ }^{1}$ First Department of Surgery, Dokkyo Medical University, Tochigi, Japan; \\ ${ }^{2}$ Department of General Surgical Science, Gunma University, Graduate School of Medicine, Maebashi, Japan
}

\begin{abstract}
Background/Aim: The purpose of this study was to identify adverse prognostic factors for patients with advanced esophageal cancer undergoing chemotherapy with docetaxel, cisplatin and 5-fluorouracil (DCF). Patients and Methods: The study cohort comprised of 45 patients with advanced esophageal cancer who underwent induction DCF therapy followed by esophagectomy or chemoradiotherapy. Treatment outcomes and factors affecting early recurrence and death were analyzed. Results: Overall 3-year survival was $61.4 \%$, and 3-year disease-free survival was $44.7 \%$. Clinically evident lymph node metastasis and clinical stage were associated with recurrence within 1 year and death within 2 years. Low maximum standardized uptake value $\left(S U V_{\max }\right)$ after induction DCF therapy and small decreases in $S U V_{\max }$ from pre- to post-DCF therapy were also predictors of recurrence and poor prognosis. Conclusion: Induction DCF therapy may be ineffective for advanced-stage esophageal cancer and clinical lymph node metastasis $(\geq N 2, \geq$ stage $I I I B)$. Moreover, small decreases in $S U V_{\max } D C F$ therapy are associated with early disease relapse and death.
\end{abstract}

Currently, treatment modalities for esophageal cancer vary according to tumor stage. In Japan, endoscopic mucosal resection and endoscopic submucosal dissection is an accepted alternative to open surgery for cancer confined to the mucosal

Correspondence to: Masanobu Nakajima, MD, Ph.D., First Department of Surgery I, Dokkyo Medical University, 880 Kitakobayashi, Mibu, Shimotsuga-gun, Tochigi 321-0293, Japan. Tel: +81 282872157; Fax: +81 282866213, e-mail: mnakajim@dokkyomed.ac.jp

Key Words: Esophageal cancer, neoadjuvant chemotherapy, DCF therapy, adverse prognostic factor. layer (1-3). Excision plus three-field lymph node dissection has contributed to improvement in survival rates of patients with locally advanced cancer (4). However, despite optimization of surgical treatment in high-volume centers, outcomes following resection of esophageal squamous cell carcinoma (ESCC) remain unsatisfactory $(5,6)$. Therefore, multimodal therapy is now frequently administered for various stages of esophageal cancer, including operable cancer (7-11). In Japan, there has been a recent trend for augmenting surgery for resectable stage II and III ESCC with preoperative neoadjuvant chemotherapy $(12,13)$.

Cisplatin with 5-fluorouracil (5-FU) (CF) has been a standard regimen for esophageal cancer. Docetaxel has recently been added to this combination and the resultant DCF regimen is now widely used (14-18). This combination is considered the most promising chemotherapy for advanced esophageal cancer, most studies reporting it to have good anticancer effects. However, associated adverse prognostic factors have not been reported.

In this study, possible adverse prognostic factors in patients with advanced esophageal cancer undergoing induction DCF therapy were assessed.

\section{Patients and Methods}

Prospective database for induction DCF. Since February 2010. we have treated patients with advanced esophageal cancer with induction DCF followed by surgery or definitive chemoradiotherapy and enrolled them in a prospective observational study. The eligibility criteria included the following: pathologically confirmed esophageal cancer without distinct invasion of neighboring structures (T4b: seventh edition TNM) (19); no distant metastases; no prior treatment; Eastern Cooperative Oncology Group performance status of 0 to 2; age 20-75 years; and adequate bone marrow, renal, and hepatic function (absolute neutrophil count $>2.0 \times 10^{9 / 1}$ and platelet count $>10.0 \times 10^{9 / 1}$; serum 
creatinine $<1.5 \mathrm{mg} / \mathrm{dl}$; aspartate aminotransferase and alanine aminotransferase $<1.5 \times$ the upper limit of normal; and total bilirubin $<1.5 \times$ the upper limit of normal). All participants provided written informed consent for inclusion and the study was approved by the Medical Ethics Committee of Dokkyo Medical University (approval number: C-234-06).

Regimen of induction DCF and following curative therapy. The DCF regimen consisted of $70 \mathrm{mg} / \mathrm{m}^{2}$ of docetaxel infused over $1 \mathrm{~h}$ on day 1 , followed by $70 \mathrm{mg} / \mathrm{m}^{2}$ of cisplatin infused over 1 hour on day 1 , and $700 \mathrm{mg} / \mathrm{m}^{2}$ of $5-\mathrm{FU}$ on days 1 to 5 as a $24 \mathrm{~h}$ continuous intravenous infusion (20). This regimen was administered at 4-week intervals, two courses being administered before curative therapy (esophagectomy or definitive chemoradiotherapy).

About 2 weeks after the second course of induction DCF, the effect of the chemotherapy was evaluated by esophagogastroduodenoscopy, computed tomography (CT) and ${ }^{18} \mathrm{~F}$-deoxyglucose positron-emission tomography (FDG-PET)/CT. Patients with maximum standard uptake $\left(\mathrm{SUV}_{\max }\right)$ in tumor of 2.0 or less were classified as chemo-responders and those with $\mathrm{SUV}_{\max } \geq 2.0$ as chemo-non-responders (21). Definitive chemoradiotherapy (CRT) was administered to all chemoresponders and to chemo-non-responders whose cancer was judged as unresectable, whereas curative esophagectomy was performed on chemo-non- responders whose tumors were considered resectable.

Study cohort. From February 2012 through December 2014, 45 patients met the eligibility criteria. Nine patients who were classified as chemo-responders and two chemo-non-responders were treated with definitive CRT after two courses of induction DCF; these nine patients were categorized as the S-CRT group and the chemo-non-responders who underwent CRT as the R-CRT group. Curative esophagectomy was performed on 34 patients who were chemo-non-responders and had resectable cancer; they were categorized as the Surgery group.

Tumor staging. All patients were staged pretreatment by endoscopy, endoscopic ultrasonography, and FDG-PET/CT. Clinical and pathological findings were classified according to the tumor, node, metastasis classification system (TNM) (7th edition) of the International Union against Cancer (UICC) (19).

Response evaluation. About 2 weeks after completion of treatment, clinical responses were evaluated according to the criteria of the Japan Esophageal Society (22). The assessment involved repeat esophagogastroduodenoscopy by two investigators who assessed the pre- and post-treatment macroscopic findings for each tumor before and CT scans of the neck, chest and abdomen. Five-millimeter continuous scans were obtained from the neck to the pelvis after intravenous injection of contrast medium. The endoscopic and CT results were discussed by the investigators and responses of primary and target lesions (maximum of five measurable lesions per organ) were classified as follows. For target lesions: complete response (CR), complete disappearance of all clinical evidence of disease; partial response $(\mathrm{PR}),>30 \%$ decrease in target lesion size; progressive disease (PD), $>20 \%$ increase in target lesion size; or stable disease (SD), increase of $<20 \%$ in tumor size or of less than $<30 \%$ in target lesion size. For non-target lesions (any other lesions, including primary tumor): $\mathrm{CR}$, disappearance of all non-target lesions, including primary lesion undetectable on endoscopy; and incomplete response/SD, persistence of one or more non-target lesion(s) or conditions for CR or PD not met on endoscopy; and PD, appearance of one or more new lesions or unequivocal progression of non-target lesion(s) or distinct growth of primary lesion or progression of esophageal stenosis compared with best condition during treatment. Overall responses were diagnosed based on a combination of response in target and non-target lesions and no new lesions. Responses were also evaluated on $\mathrm{SUV}_{\max }$ in FDG-PET studies, as described above.

Histopathological responses to treatment were classified in accordance with the criteria of the Japan Esophageal Society. Briefly, the viability of residual tumor cells was assessed as follows: Grade 0. no necrosis, cellular or structural changes evident; grade 1a, necrosis or tumor comprising less than one-third of lesion, or only cellular or structural changes present in varying amounts; grade $1 \mathrm{~b}$, necrosis or tumor comprising no more than two-thirds of lesion; grade 2, necrosis or tumor comprising more than two-thirds of lesion with some viable tumor cells remaining; grade 3, entire lesion necrotic or replaced by fibrosis with or without granulomatous changes (no viable tumor cells seen).

Follow-up. The patients were followed-up at our clinic at least every 3 months. All patients were followed up for more than 24 months, the median follow-up from starting chemotherapy to death or last visit being 33.2 months.

Statistical analysis. Categorical analysis of variables was performed using either the Chi-squared or Fisher's exact test, as appropriate. Continuous data were compared with the Mann-Whitney $U$-test. Survival curves were plotted according to the Kaplan-Meier method and any differences were analyzed using the log-rank test. Multivariate analysis was performed using logistic regression. Differences were considered to be significant when the $p$-value was less than 0.05. All statistical analyses were carried out using $\mathrm{R}$ software (version 3.3.1).

\section{Results}

Characteristics of patients. The mean patient age was 64.6 years. There were 40 men and five women (ratio 8:1). The predominant histological type was squamous cell carcinoma $(n=43)$, the remaining two tumors were adenocarcinomas. Twenty-one tumors were located in the mid-thoracic, 14 in the lower, and 10 in the upper thoracic esophagus. Most tumors had invaded to the adventitia or beyond ( $\mathrm{T} 3$ or $\mathrm{T} 4 \mathrm{a}$ ) and lymph node metastases were detected in 39 patients $(86.7 \%)$. Clinical stages were as follows: seven stage II, 37 stage III, and one stage IV.

Clinical response to DCF therapy. $\mathrm{CR}, \mathrm{PR}, \mathrm{SD}$, and $\mathrm{PD}$ were achieved in two $(4.4 \%), 32(71.1 \%)$, nine $(20 \%)$, and two (4.4\%) cases, respectively. The clinical response rate (cRR; CR plus PR) was $75.6 \%$ and the disease control rate (DCR; CR, PR, and SD) $95.6 \%$.

Relationship between clinical response to DCF therapy and type of curative therapy. Patient characteristics according to curative therapy received are shown in Table 
I. Age, sex, tumor location, depth of tumor invasion, nodal status, and tumor stage did not differ between the three treatment groups. The relationship between clinical responses after induction chemotherapy and curative therapy received were as follows: CR and PR occurred in one $(11.1 \%)$ and eight $(88.9 \%)$ patients, respectively, in the S-CRT group. PR, SD, and PD occurred in 25 (73.5\%), eight $(23.5 \%)$, and one $(2.9 \%)$ patient, respectively, in the Surgery group. SD and PD each occurred in one patient in the R-CRT group. The responses rates in the curative therapy groups were $100 \%, 73.5 \%$, and $0 \%$, respectively. Clinical response was significantly related to type of curative therapy $(p<0.0001)$.

Outcomes after curative therapy. Nine patients in the S-CRT group achieved CR, whereas both patients in the R-CRT group had PD. Pathology-assessed outcomes in the 34 patients in the Surgery group were: Grade 0: 1, grade 1a: 23, grade $1 \mathrm{~b}: 3$, grade $2: 3$, and grade $3: 4$. Twenty-five patients had no residual tumor (R0) $(73.5 \%)$, six had suspicion of residual tumor or microscopic residual tumor (R1) (17.6\%), and three macroscopic residual tumor $(8.8 \%)$.

Survival. The overall survival (OS) and disease-free survival (DFS) of the 45 patients are shown in Figure 1. Three-year OS was $53.6 \%$ and 3-year DFS $42.2 \%$. OS and DFS according to curative therapy are shown in Figure 2. In the S-CRT group, 3-year OS was $77.8 \%$, whereas 3-year DFS was $66.7 \%$. In the Surgery group, 3-year OS was $46.1 \%$ and 3 -year DFS was $38.2 \%$. The two patients in the R-CRT group died within 1 year.

Factors affecting recurrence withinl year and death within 2 years in the whole patient cohort. Adverse prognostic factors are summarized in Table II. Clinical lymph node metastases $\geq N 2$, clinical stage $\geq \mathrm{IIIB}$, and high $\mathrm{SUV}_{\max }$ after induction DCF therapy were found to be significantly associated with recurrence within 1 year and death within 2 years. Small decreases in $\mathrm{SUV}_{\max }$ from pre- to postinduction DCF therapy were also associated with poor prognosis. However, none of these were independent prognostic factors according to multivariate logistic regression (data not shown).

Factors affecting recurrence within 1 year and death within 2 years in patients underwent esophagectomy. Adverse prognostic factors in patients who underwent esophagectomy are summarized in Table III. Clinical lymph node metastases $\geq \mathrm{N} 2$, clinical stage IIIB or higher, and post-chemotherapy $\mathrm{SUV}_{\max }$ affected recurrence within 1 year and death within 2 years in this group. However, these factors were not independent prognostic factors according to multivariate logistic regression (data not shown).
Table I. Patients characteristics according to type of curative therapy received.

\begin{tabular}{lcccc}
\hline Factor & $\begin{array}{c}\text { S-CRT } \\
\text { group } \\
(\mathrm{n}=9)\end{array}$ & $\begin{array}{c}\text { Surgery } \\
\text { group } \\
(\mathrm{n}=34)\end{array}$ & $\begin{array}{c}\text { R-CRT } \\
\text { group } \\
(\mathrm{n}=2)\end{array}$ & $p$-Value \\
& $68.2 \pm 5.9$ & $64 \pm 10.3$ & $62.0 \pm 2.0$ & NS \\
\hline Age, years & 9 & 30 & 1 & 0.2577 \\
Gender & 0 & 4 & 1 & \\
Male & & & & 0.1658 \\
Female & 4 & 6 & 0 & \\
Location & 3 & 16 & 2 & \\
Upper & 2 & 12 & 0 & \\
Middle & & & & 0.8203 \\
Lower & 0 & 1 & 0 & \\
Depth of tumor inavsion & 0 & 1 & 0 & \\
T1b & 2 & 27 & 1 & \\
2 & 7 & 5 & 1 & \\
3 & & & & 0.3215 \\
4a & 1 & 5 & 0 & \\
Lymph node metastasis & 5 & 12 & 0 & \\
N0 & 2 & 12 & 0 & \\
1 & 1 & 5 & 2 & \\
2 & & & & 0.2651 \\
3 & 1 & 6 & 0 & \\
Stage & 7 & 28 & 2 & \\
II & 1 & 0 & 0 & \\
III & & & & \\
IV & & & & \\
\hline
\end{tabular}

S-CRT: Sensitive-chemoradiothrapy; R-CRT: resistant-chemoradiotherapy; NS: not significant.

\section{Discussion}

DCF is currently used to treat patients with advanced esophageal cancer and is reportedly very effective $(23,24)$. However, it has a high incidence of adverse events $(15,25)$. Therefore, administration should be avoided in patients in whom it will likely be ineffective. We therefore investigated possible adverse prognostic factors associated with induction DCF therapy in this series.

Neoadjuvant chemotherapy followed by esophagectomy is currently the mainstay of treatment for stage II and III esophageal cancer (13). However, esophagectomy for advanced esophageal cancer is very invasive and has a high incidence of postoperative morbidity and mortality $(26,27)$, thus quality of life after surgery may be poor (28). CRT is the second therapeutic modality to consider for resectable esophageal cancer (12). Although the quality of life after chemoradiotherapy varies, organ preservation is the greatest advantage over esophagectomy provided CR is achieved. At our Institution, curative therapy (esophagectomy or chemoradiotherapy) is selected according to the clinical effect of induction chemotherapy. We consider FDG-PET findings to be a useful aid in making therapy decisions (21). In this study, the 3-years OS for the whole cohort was 
A

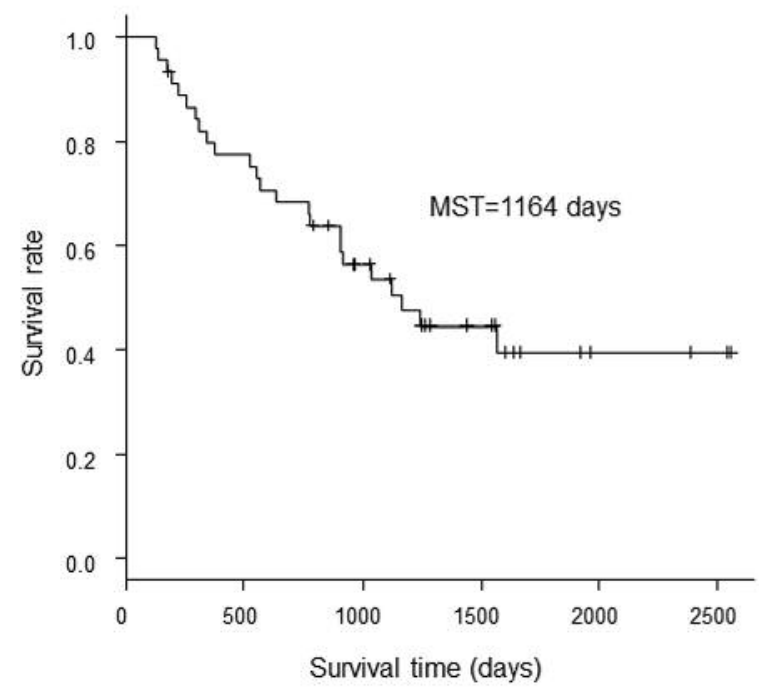

B

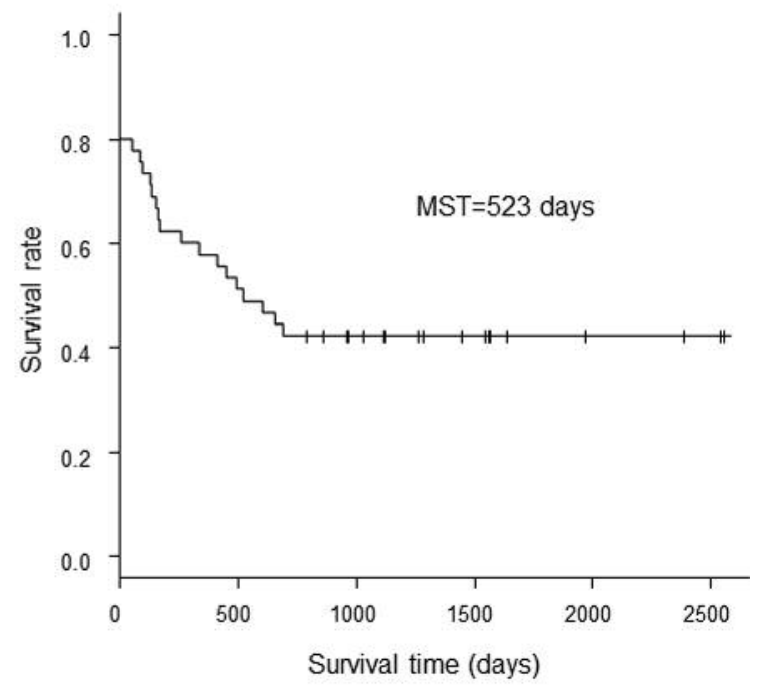

Figure 1. Survival curves after induction chemotherapy with docetaxel, cisplatin, 5-fluorouracil. A: Overall survival of the 45 patients. B: Diseasefree survival. MST: Median survival time.

A

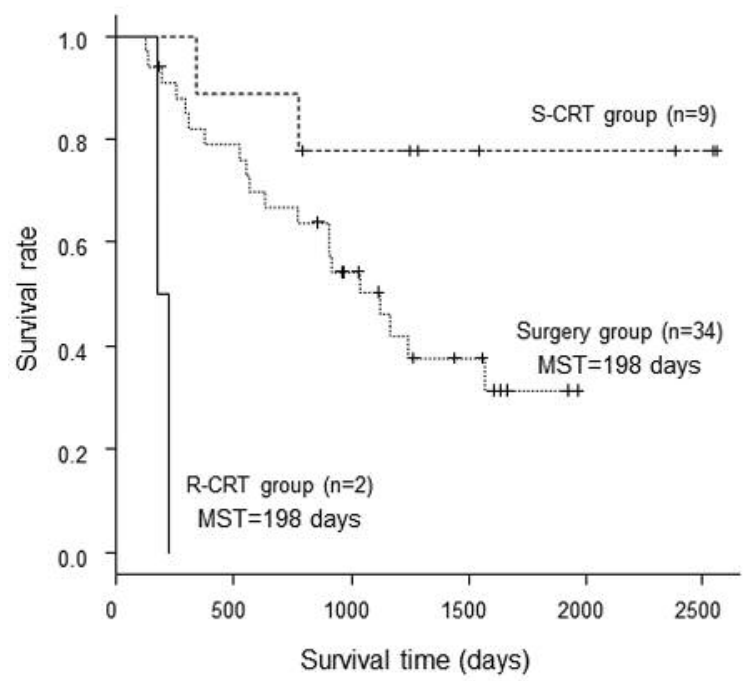

B

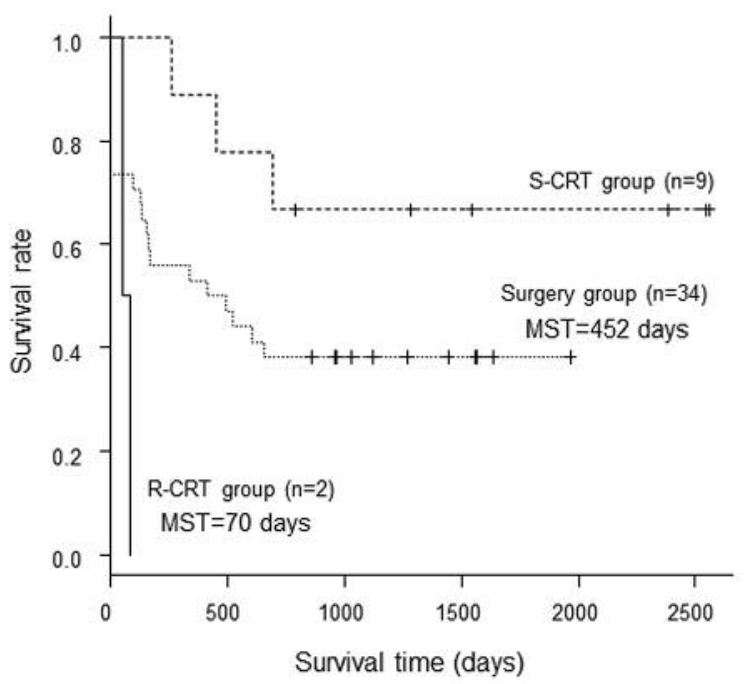

Figure 2. Survival curves according to curative therapies received. A: Overall survival of the 45 patients ( $p<0.0001)$. B: Disease-free survival $(p=0.0142)$. MST: Median survival time, NA: not applicable.

53.6\%. Given that this included 15 patients with stage IIIC and IV disease, we consider this result acceptable. Survival of the nine patients who underwent CRT after being identified as chemo-responders was significantly superior to that of the patients who underwent surgery. Thus, selection of radical therapy according to response to induction DCF therapy is a useful guide to individualizing treatment.
We found that clinical lymph node metastases N2 or higher, stage IIIB or higher, and higher $\mathrm{SUV}_{\max }$ after induction DCF therapy were associated with recurrence within 1 year. Moreover, these attributes were associated with death within 2 years, as were small decreases in $\mathrm{SUV}_{\max }$.

Clinical evidence of lymph node metastases has been accepted as a definitive prognostic factor for esophageal 
Table II. Factors affecting recurrence within 1 year and death within 2 years in the whole patient cohort.

\begin{tabular}{|c|c|c|c|c|c|c|}
\hline \multirow[t]{2}{*}{ Factor } & \multicolumn{3}{|c|}{ Relapse within 1 year } & \multicolumn{3}{|c|}{ Death within 2 years } \\
\hline & $\begin{array}{c}\text { No } \\
(\mathrm{n}=26)\end{array}$ & $\begin{array}{c}\text { Yes } \\
(\mathrm{n}=19)\end{array}$ & $p$-Value & $\begin{array}{c}\text { No } \\
(\mathrm{n}=30)\end{array}$ & $\begin{array}{c}\text { Yes } \\
(\mathrm{n}=15)\end{array}$ & $p$-Value \\
\hline Age, years & 65.7 & 62.9 & 0.2645 & 64.6 & 64.3 & 0.9110 \\
\hline Gender, $\mathrm{n}$ & & & 0.9150 & & & 0.7373 \\
\hline Male & 23 & 17 & & 27 & 13 & \\
\hline Female & 3 & 2 & & 3 & 2 & \\
\hline Location, $\mathrm{n}$ & & & 0.9447 & & & 0.5698 \\
\hline Upper & 6 & 4 & & 8 & 2 & \\
\hline Middle & 11 & 9 & & 13 & 7 & \\
\hline Lower & 9 & 6 & & 9 & 6 & \\
\hline Depth of tumor invasion & & & 0.4995 & & & 0.7827 \\
\hline $1 \mathrm{~b}$ & 0 & 1 & & 1 & 0 & \\
\hline 2 & 1 & 0 & & 1 & 0 & \\
\hline 3 & 21 & 14 & & 23 & 12 & \\
\hline $4 \mathrm{a}$ & 4 & 4 & & 5 & 3 & \\
\hline Lymph node metastasis, $\mathrm{n}$ & & & 0.0094 & & & 0.0010 \\
\hline 0 & 6 & 0 & & 6 & 0 & \\
\hline 1 & 12 & 4 & & 15 & 1 & \\
\hline 2 & 6 & 10 & & 6 & 10 & \\
\hline 3 & 2 & 5 & & 3 & 4 & \\
\hline Stage, $\mathrm{n}$ & & & 0.0030 & & & 0.0193 \\
\hline IIA & 6 & 0 & & 6 & 0 & \\
\hline IIB & 0 & 1 & & 1 & 0 & \\
\hline IIIA & 10 & 1 & & 10 & 1 & \\
\hline IIIB & 3 & 9 & & 4 & 8 & \\
\hline IIIC & 6 & 8 & & 8 & 6 & \\
\hline IV & 1 & 0 & & 1 & 0 & \\
\hline Tumor response, $\mathrm{n}$ & & & 0.3274 & & & 0.0906 \\
\hline CR & 1 & 0 & & 1 & 0 & \\
\hline PR & 21 & 12 & & 25 & 8 & \\
\hline SD & 3 & 6 & & 3 & 6 & \\
\hline $\mathrm{PD}$ & 1 & 1 & & 1 & 1 & \\
\hline Rate of SUV $\mathrm{max}_{\max }$ decrease, $\%$ & 63.1 & 48.3 & 0.2281 & 65.2 & 40.1 & 0.0465 \\
\hline $\mathrm{SUV}_{\max }$ after ICT & 5.1 & 8.1 & 0.0421 & 4.6 & 9.7 & 0.0036 \\
\hline
\end{tabular}

CR: Complete response; PR: partial response; SD: stable disease; PD: progressive disease; ICT: induction chemotherapy; $\mathrm{SUV}_{\max }$ : maximum standardized uptake value.

cancer (29). In this study, lymph node status before induction chemotherapy was associated with recurrence and prognosis. Patients with many metastatic lymph nodes tended to still have detectable lymph node metastases after two courses of induction chemotherapy (data not shown). Yasuda et al. reported that lymph node status according to FDG-PET after neoadjuvant chemotherapy, not the effects on the primary tumor, is a critical criterion for evaluating prognosis (30). Even after DCF therapy, it seems that multiple lymph node metastases do not completely resolve; this may be linked with disease recurrence after curative treatments and poor prognosis.

In this series, 34 out of 45 patients $(75.6 \%)$ underwent esophagectomy and relapse occurred within 1 year in 16 of them. Clinical lymph node metastases N2 or higher, stage IIIB or higher, and high $\mathrm{SUV}_{\max }$ after induction DCF therapy were associated with recurrence and death.

Our findings indicate that two courses of DCF therapy is insufficient for patients with lymph node metastases N2 or higher and stage IIIB or higher, who clearly require more potent therapy. The JCOG1109, NExT study is currently in progress in Japan (31). This is a three-armed, randomized, controlled trial is designed to assess the superiority of preoperative DCF and of CRT with CF over $\mathrm{CF}$ alone for $\mathrm{OS}$ in patients with locally advanced esophageal cancer. Three courses of DCF therapy at 3week intervals and CRT with CF may prove to be more effective. DCF-RT is reportedly a promising therapy for 
Table III. Factors affecting recurrence within 1 year and death within 2 years in patients who underwent esophagectomy.

\begin{tabular}{|c|c|c|c|c|c|c|}
\hline \multirow[b]{2}{*}{ Factor } & \multicolumn{3}{|c|}{ Relapse within 1 year } & \multicolumn{3}{|c|}{ Death within 2 years } \\
\hline & $\begin{array}{c}\text { No } \\
(\mathrm{n}=18)\end{array}$ & $\begin{array}{c}\text { Yes } \\
(n=16)\end{array}$ & $p$-Value & $\begin{array}{c}\text { No } \\
(\mathrm{n}=22)\end{array}$ & $\begin{array}{c}\text { Yes } \\
(\mathrm{n}=12)\end{array}$ & $p$-Value \\
\hline Age, years & 65.2 & 62.6 & 0.4037 & 63.8 & 64.3 & 0.8747 \\
\hline Gender, $\mathrm{n}$ & & & 0.3467 & & & 0.6465 \\
\hline Male & 15 & 15 & & 19 & 11 & \\
\hline Female & 3 & 1 & & 3 & 1 & \\
\hline Location, $\mathrm{n}$ & & & 0.5666 & & & 0.8445 \\
\hline Upper & 2 & 4 & & 4 & 2 & \\
\hline Middle & 9 & 7 & & 11 & 5 & \\
\hline Lower & 7 & 5 & & 7 & 5 & \\
\hline Depth of tumor invasion, $\mathrm{n}$ & & & 0.4892 & & & 0.7589 \\
\hline $1 \mathrm{~b}$ & 0 & 1 & & 1 & 0 & \\
\hline 2 & 1 & 0 & & 1 & 0 & \\
\hline 3 & 15 & 12 & & 17 & 10 & \\
\hline $4 \mathrm{a}$ & 2 & 3 & & 3 & 2 & \\
\hline Lymph node metastasis, $\mathrm{n}$ & & & 0.0239 & & & 0.0019 \\
\hline 0 & 5 & 0 & & 5 & 0 & \\
\hline 1 & 8 & 4 & & 11 & 1 & \\
\hline 2 & 3 & 9 & & 3 & 9 & \\
\hline 3 & 2 & 3 & & 3 & 2 & \\
\hline Stage, $\mathrm{n}$ & & & 0.0030 & & & 0.0246 \\
\hline IIA & 5 & 0 & & 5 & 0 & \\
\hline IIB & 0 & 1 & & 1 & 0 & \\
\hline IIIA & 8 & 1 & & 8 & 1 & \\
\hline IIIB & 2 & 9 & & 3 & 7 & \\
\hline IIIC & 3 & 8 & & 5 & 4 & \\
\hline Tumor response, $\mathrm{n}$ & & & 0.4172 & & & 0.1556 \\
\hline $\mathrm{PR}$ & 14 & 11 & & 18 & 7 & \\
\hline SD & 3 & 5 & & 3 & 5 & \\
\hline $\mathrm{PD}$ & 1 & 0 & & 1 & 0 & \\
\hline Rate of SUV $\mathrm{max}_{\max }$ decrease, $\%$ & 53.1 & 52.4 & 0.9618 & 57.8 & 43.4 & 0.3351 \\
\hline $\mathrm{SUV}_{\max }$ after ICT & 6.6 & 7.2 & 0.7296 & 5.7 & 9 & 0.0374 \\
\hline
\end{tabular}

CR: Complete response; PR: partial response; SD: stable disease; PD: progressive disease; ICT: induction chemotherapy; $\mathrm{SUV}_{\max }$ : maximum standardized uptake value.

advanced esophageal cancer (32). These more potent therapies and new agents such as immune checkpoint inhibitors administered as induction therapy may achieve better outcomes (33).

A previous study found that pre-chemotherapy FDG uptake by PET is not a significant predictor of response (34). However, low SUV or large decreases in SUV after chemotherapy are reportedly predictors of response (35). In the present study, high SUV and small decreases in SUV after two courses of DCF were found to be useful for predicting disease recurrence and death. Thus, additional therapy (e.g. CRT or additional courses of DCF) should be considered for such patients.

In conclusion, two courses of induction DCF therapy and subsequent esophagectomy and CRT may be ineffective in patients with esophageal cancer and clinical lymph node metastases N2 or higher and stage IIIB or higher. Stronger multimodality therapy should be considered for such patients. Moreover, early disease relapse and death are of deep concern in patients with small decreases in SUV on FDG-PET after DCF therapy. Additional therapy should also be considered for these patients.

\section{Conflicts of Interest and Funding}

The Authors declare no conflicts of interest and received no financial support specifically for this study.

\section{Acknowledgements}

The Authors thank Hitomi Ozeki, Yuki Ohashi and Nozomi Yuzawa for their skillful assistance. 


\section{References}

1 Ono S, Fujishiro M, Niimi K, Goto O, Kodashima S, Yamamichi $\mathrm{N}$ and Omata $\mathrm{M}$ : Long-term outcomes of endoscopic submucosal dissection for superficial esophageal squamous cell neoplasms. Gastrointest Endosc 70: 860-866, 2009.

2 Tsujii Y, Nishida T, Nishiyama O, Yamamoto K, Kawai N, Yamaguchi S, Yamada T, Yoshio T, Kitamura S, Nakamura T, Nishihara A, Ogiyama H, Nakahara M, Komori M, Kato M, Hayashi Y, Shinzaki S, Iijima H, Michida T, Tsujii M and Takehara T: Clinical outcomes of endoscopic submucosal dissection for superficial esophageal neoplasms: a multicenter retrospective cohort study. Endoscopy 47: 775-783, 2015.

3 Pech O, Manner H and Ell C: Endoscopic resection. Gastrointest Endosc Clin N Am 21: 81-94, 2011.

4 Fujita H, Kakegawa T, Yamana H, Shima I, Toh Y, Tomita Y, Fujii T, Yamasaki K, Higaki K, Noake T, Ishibashi $\mathrm{N}$ and Mizutani K: Mortality and morbidity rates, postoperative course, quality of life, and prognosis after extended radical lymphadenectomy for esophageal cancer. Comparison of threefield lymphadenectomy with two-field lymphadenectomy. Ann Surg 222: 654-662, 1995.

5 Mariette C, Piessen G and Triboulet JP: Therapeutic strategies in oesophageal carcinoma: role of surgery and other modalities. Lancet Oncol 8: 545-553, 2007.

6 Tachimori Y, Ozawa S, Numasaki H, Fujishiro M, Matsubara H, Oyama T, Shinoda M, Toh Y, Udagawa $H$ and Uno $T$ : Comprehensive Registry of Esophageal Cancer in Japan, 2008. Esophagus 12: 130-157, 2015.

7 Nishimura Y, Hiraoka M, Koike R, Nakamatsu K, Itasaka S, Kawamura M, Negoro Y, Araki N, Ishikawa H, Fujii T and Mitsuhashi N: Long-term follow-up of a randomized phase II study of cisplatin/5-FU concurrent chemoradiotherapy for esophageal cancer (KROSG0101/JROSG021). Jpn J Clin Oncol 42: 807-812, 2012.

8 Emi M, Hihara J, Hamai Y, Aoki Y, Okada M, Kenjo M and Murakami Y: Neoadjuvant chemoradiotherapy with docetaxel, cisplatin, and 5-fluorouracil for esophageal cancer. Cancer Chemother Pharmacol 69: 1499-1505, 2012.

9 Kato H, Fukuchi M, Manda R, Faried A, Takita J, Nakajima M, Miyazaki T, Sohda M, Fukai Y, Masuda N, Tsukada K and Kuwano H: The effectiveness of planned esophagectomy after neoadjuvant chemoradiotherapy for advanced esophageal carcinomas. Anticancer Res 24: 4091-4096, 2004.

10 Morita M, Toh Y, Saeki H, Sugiyama M, Ohgaki K, Maehara S, Minami K, Ikeda Y, Sakaguchi Y, Okamura T, Uehara S and Maehara Y: Clinical significance of chemoradiotherapy and surgical resection for cT4 esophageal cancer. Anticancer Res 32: 3275-3282, 2012.

11 Lee JL, Kim SB, Jung HY, Park SI, Kim DK, Kim JH, Song HY, Kim WK, Lee JS and Min YI: Efficacy of neoadjuvant chemoradiotherapy in resectable esophageal squamous cell carcinoma - a single institutional study. Acta Oncol 42: 207-217, 2003.

12 Kuwano H, Nishimura Y, Oyama T, Kato H, Kitagawa Y, Kusano M, Shimada H, Takeuchi H, Toh Y, Doki Y, Naomoto Y, Matsubara $\mathrm{H}$, Miyazaki $\mathrm{T}$, Muto $\mathrm{M}$ and Yanagizawa $\mathrm{Y}$ : Guideline for Diagnosis and Treatment of Carcinoma of the Esophagus April 2012 edited by the Japan Esophageal Society. Esophagus 12: 1-30, 2012.
13 Ando N, Kato H, Igaki H, Shinoda M, Ozawa S, Shimizu H, Nakamura T, Yabusaki H, Aoyama N, Kurita A, Ikeda K, Kanda T, Tsujinaka T, Nakamura $\mathrm{K}$ and Fukuda H: A randomized trial comparing postoperative adjuvant chemotherapy with cisplatin and 5-fluorouracil versus preoperative chemotherapy for localized advanced squamous cell carcinoma of the thoracic esophagus (JCOG9907). Ann Surg Oncol 19: 68-74, 2012.

14 Ajani JA, Moiseyenko VM, Tjulandin S, Majlis A, Constenla M, Boni C, Rodrigues A, Fodor M, Chao Y, Voznyi E, Marabotti C and Van Cutsem E; V-325 Study Group: Clinical benefit with docetaxel plus fluorouracil and cisplatin compared with cisplatin and fluorouracil in a phase III trial of advanced gastric or gastroesophageal cancer adenocarcinoma: the V-325 Study Group. J Clin Oncol 25: 3205-3209, 2007.

15 Yamasaki M, Miyata H, Tanaka K, Shiraishi O, Motoori M, Peng YF, Yasuda T, Yano M, Shiozaki H, Mori M and Doki Y: Multicenter phase I/II study of docetaxel, cisplatin and fluorouracil combination chemotherapy in patients with advanced or recurrent squamous cell carcinoma of the esophagus. Oncology 80: 307-313, 2011.

16 Watanabe M, Nagai Y, Kinoshita K, Saito S, Kurashige J, Karashima R, Hirashima K, Sato N, Imamura Y, Hiyoshi Y, Baba Y, Iwagami S, Miyamoto Y, Iwatsuki M, Hayashi N and Baba H: Induction chemotherapy with docetaxel/cisplatin/5fluorouracil for patients with node-positive esophageal cancer. Digestion 83: 146-152, 2011.

17 Ferri LE, Ades S, Alcindor T, Chasen M, Marcus V, Hickeson M, Artho G and Thirlwell MP: Perioperative docetaxel, cisplatin, and 5-fluorouracil (DCF) for locally advanced esophageal and gastric adenocarcinoma: a multicenter phase II trial. Ann Oncol 23: 1512-1517, 2012.

18 Nomura M, Oze I, Abe T, Komori A, Narita Y, Masuishi T, Taniguchi H, Kadowaki S, Ura T, Andoh M, Kawai R, Uemura N, Ishihara M, Tanaka T, Tajika M, Niwa Y, Muro K and Muto M: Impact of docetaxel in addition to cisplatin and fluorouracil as neoadjuvant treatment for resectable stage III or T3 esophageal cancer: a propensity score-matched analysis. Cancer Chemother Pharmacol 76: 357-363, 2015.

19 Edge SB, Byrd DR, Compton CC, Fritz AG, Greene FL and TrottiA: American Joint Committee on Cancer (AJCC) Cancer Staging Manual. Seventh Edition. Chicago: Springer, 2010.

20 Satomura H, Nakajima M, Sasaki K, Yamaguchi S, Domeki Y, Takahashi M, Muroi H, Kubo T, Kikuchi M, Otomo H, Ihara K and Kato H: Phase I dose-escalation study of docetaxel, cisplatin, and 5-fluorouracil combination chemotherapy in patients with advanced esophageal carcinoma. Int Surg 100: 1153-1158, 2015.

21 Nakajima M, Muroi H, Takahashi M, Domeki Y, Ihara K, Kubo T, Shida Y, Sugawara A, Satomura H, Otsuka K, Okamoto K, Ogata H, Yamaguchi S, Sasaki K, and Kato H: Selection of the treatment for advanced esophageal cancer and adjuvant therapies. Jpn J Cancer Clin 61: 191-195, 2015 (in Japanese).

22 Japan Esophageal Society: Japanese classification of esophageal cancer, tenth edition: part II and III. Esophagus 6: 71-94, 2009.

23 Watanabe M, Baba Y, Yoshida N, Ishimoto T, Nagai Y, Iwatsuki $\mathrm{M}$, Iwagami $\mathrm{S}$ and Baba $\mathrm{H}$ : Outcomes of preoperative chemotherapy with docetaxel, cisplatin, and 5-fluorouracil followed by esophagectomy in patients with resectable nodepositive esophageal cancer. Ann Surg Oncol 21: 2838-2844, 2014. 
24 Yokota T, Hatooka S, Ura T, Abe T, Takahari D, Shitara K, Nomura M, Kondo C, Mizota A, Yatabe Y, Shinoda M and Muro $\mathrm{K}$ : Docetaxel plus 5-fluorouracil and cisplatin (DCF) induction chemotherapy for locally advanced borderline-resectable T4 esophageal cancer. Anticancer Res 31: 3535-3541, 2011.

25 Hara H, Tahara M, Daiko H, Kato K, Igaki H, Kadowaki S, Tanaka Y, Hamamoto Y, Matsushita H, Nagase M and Hosoya Y: Phase II feasibility study of preoperative chemotherapy with docetaxel, cisplatin, and fluorouracil for esophageal squamous cell carcinoma. Cancer Sci 104: 1455-1460, 2013.

26 Committee for Scientific Affairs, The Japanese Association for Thoracic Surgery, Masuda M, Kuwano H, Okumura M, Arai H, Endo S, Doki Y, Kobayashi J, Motomura N, Nishida H, Saiki Y, Tanaka F, Tanemoto K, Toh Y, and Yokomise H: Thoracic and cardiovascular surgery in Japan during 2013: Annual report by The Japanese Association for Thoracic Surgery. Gen Thorac Cardiovasc Surg 63: 670-701, 2015.

27 Raymond DP, Seder CW, Wright CD, Magee MJ, Kosinski AS, Cassivi SD, Grogan EL, Blackmon SH, Allen MS, Park BJ, Burfeind WR, Chang AC, DeCamp MM, Wormuth DW, Fernandez FG and Kozower BD: Predictors of major morbidity or mortality after resection for esophageal cancer: A Society of Thoracic Surgeons General Thoracic Surgery Database risk adjustment model. Ann Thorac Surg 102: 207-214, 2016.

28 Pinto E, Cavallin F, Alfieri R, Saadeh LM, Mantoan S, Cagol M, Castoro $\mathrm{C}$ and Scarpa M: Impact of esophagectomy for cancer on patients' occupational status. Eur J Surg Oncol 42: 103-109, 2016.

29 Akutsu Y and Matsubara H: The significance of lymph node status as a prognostic factor for esophageal cancer. Surg Today 41: 1190-1195, 2011.

30 Yasuda T, Yano M, Miyata H, Yamasaki M, Takiguchi S, Fujiwara Y and Doki Y: Prognostic significance of (18)Ffluorodeoxyglucose positron emission tomography (FDG-PET)positive lymph nodes following neoadjuvant chemotherapy and surgery for resectable thoracic esophageal squamous cell carcinoma. Ann Surg Oncol 22: 2599-2607, 2015.
31 Nakamura K, Kato K, Igaki H, Ito Y, Mizusawa J, Ando N, Udagawa H, Tsubosa Y, Daiko H, Hironaka S, Fukuda H and Kitagawa Y; Japan Esophageal Oncology Group/Japan Clinical Oncology Group: Three-arm phase III trial comparing cisplatin plus 5-FU (CF) versus docetaxel, cisplatin plus 5-FU (DCF) versus radiotherapy with $\mathrm{CF}$ (CF-RT) as preoperative therapy for locally advanced esophageal cancer (JCOG1109, NExT study). Jpn J Clin Oncol 43: 752-755, 2013.

32 Miyazaki T, Sohda M, Tanaka N, Suzuki S, Ieta K, Sakai M, Sano A, Yokobori T, Inose T, Nakajima M, Fukuchi M, Ojima $\mathrm{H}$, Kato $\mathrm{H}$ and Kuwano $\mathrm{H}$ : Phase I/II study of docetaxel, cisplatin, and 5-fluorouracil combination chemoradiotherapy in patients with advanced esophageal cancer. Cancer Chemother Pharmacol 75: 449-455, 2015.

33 Raufi AG and Klempner SJ: Immunotherapy for advanced gastric and esophageal cancer: preclinical rationale and ongoing clinical investigations. J Gastrointest Oncol 6: 561-569, 2015.

34 Tani Y, Nakajima M, Kikuchi M, Ihara K, Muroi H, Takahashi M, Domeki Y, Okamoto K, Yamaguchi S, Sasaki K, Tsuchioka T, Sakamoto $\mathrm{S}$ and Kato H: ${ }^{18} \mathrm{~F}$-Fluorodeoxyglucose positronemission tomography for evaluating the response to neoadjuvant chemotherapy in advanced esophageal cancer. Anticancer Res 36: 367-373, 2016.

35 Kato H, Fukuchi M, Miyazaki T, Nakajima M, Kimura H, Faried A, Sohda M, Fukai Y, Masuda N, Manda R, Ojima H, Tsukada $\mathrm{K}$, Oriuchi N, Endo $\mathrm{K}$ and Kuwano H: Positron-emission tomography in esophageal cancer. Esophagus 2: 111-121, 2005.

Received October 25, 2017

Revised November 27, 2017

Accepted November 30, 2017 